\title{
Correction to "Reported Practice Patterns Among Family Physicians With a Geriatrics Certificate of Added Qualifications"
}

In the above-mentioned article, ${ }^{1}$ the electronic version differs from the print version due to data reporting errors. The electronic version on the Journal of the American Board of Family Medicine website has been corrected. We apologize for the error, and we regret any confusion or inconvenience it may have caused.

doi: 10.3122/jabfm.2016.06.160293

\section{Reference}

1. Peterson LE, Cochrane A, Bazemore AW, Petterson S. Reported practice patterns among family physicians with a geriatrics certificate of added qualifications. J Am Board Fam Med 2015;28:314-5. 